1 Communication in J Avian Biology

\title{
Movements and activities of male Black-tailed Gulls in breeding and sabbatical years
}

4

5

(1)

(1)

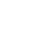

1. Laboratory of Marine Ecology, Graduate school of Fisheries Sciences, Hokkaido University. 3-1-1 Minatocho, Hakodate, Hokkaido. 041-8611, Japan.

2. Laboratory of Environmental Zoology, Faculty of Agriculture, Meijo University. 1-501 Shiogamaguchi, Tenpaku, Nagoya, Aichi, 468-8502, Japan.

3. National Institute of Polar Research, 10-3 Midoricho, Tachikawa, Tokyo 190-8518, Japan.

\section{Laboratory of Landscape Design, Faculty of Agriculture, Meijo University. 1-501}

Shiogamaguchi, Tenpaku, Nagoya, Aichi, 468-8502, Japan.

5. British Antarctic Survey, Natural Environment Research Council, High Cross, Madingley Road, Cambridge CB3 0ET, United Kingdom.

*Corresponding author (present address)

Laboratory of Environmental Zoology, Faculty of Agriculture, Meijo University, 1-501

Shiogamaguchi, Tenpaku-ku, Nagoya, Aichi, 468-8502, JAPAN, TEL: +81-52-8382454, FAX: +81-52-8357450, E-mail: kntkzma@gmail.com 


\section{ABSTRACT}

26 Long-lived animals sometimes skip one or more breeding seasons; however, little is

27 known about their movements and activities during such 'sabbatical' periods. Here we

28 present novel data on year-round movements and activities of two male Black-tailed

29 Gulls Larus crassirostris during a sabbatical year. We compare the data with those in a

30 year when they bred and with those of two other breeding males. The year-round

31 migration routes of two sabbatical males were consistent with those of the breeding

32 males: they returned to the breeding area but did not visit the colony in the sabbatical

33 year. They landed more frequently on water (a potential index of foraging effort) during

34 the non-breeding autumn and winter prior to the sabbatical year than before breeding.

35 Sabbatical gulls may forage more intensively to recover body condition immediately

36 after breeding.

37

38 Key words: breeding decision, geolocator, intermittent breeding, migration, sabbatical 
In long-lived animals, the reproductive effort expended during a breeding attempt may negatively impact an individual's future reproductive potential or survival (Williams 1966; Stearns 1992). Therefore, individuals may skip breeding during one or more

'sabbatical' seasons under conditions where breeding is likely to have a strong negative impact upon their future reproductive potential (Stearns 1992). Sabbatical periods have been observed in many seabird species (e.g., Rice and Kenyon 1962; Calladine and Harris 1997; Le Bohec et al. 2007). To date, the distributions, movements, or activities of seabirds during sabbatical years have been little studied, since individuals that skip breeding usually do not attend nest-sites, and thus it is difficult to monitor their behavior. However, new Global Location Sensor (GLS) devices are capable of recording post-breeding migratory routes and activities for over two years, and thus facilitate the collection of movement and activity data during avian sabbatical years.

Many territorial nesting seabird species return to their breeding colony (or the area around the colony) even in a sabbatical year in order to maintain their breeding territory (e.g., Calladine and Harris 1997; Danchin and Cam 2002; Phillips et al. 2005). In such species, the migratory movements of individuals during a sabbatical year might be expected to follow similar patterns (i.e., routes and timing) to those in breeding years. However, the foraging activities of individuals in sabbatical years might differ from those in breeding years. In some seabird species, the energetic or physiological state of individuals prior to breeding (which may reflect their foraging condition during post-breeding migration) is higher in breeding years than in sabbatical years (Giudici et al. 2010; Goutte et al. 2010).

In the present study, we investigated the year-round movements and activities 
of four territorial nesting Black-tailed Gulls Larus crassirostris (Kazama et al. 2012)

using GLS during one (two males) or two years (two males). The latter two males skipped a breeding season, did not return to the nest-site, and so bred intermittently. We predicted that sabbatical Black-tailed Gulls would show similar migratory movements to breeding individuals (i.e., summer near the colony), but that they would forage more intensively in order to improve their body condition during the year prior to breeding than in the year before a sabbatical.

\section{METHODS}

Field work The study was conducted on Rishiri Island $\left(45^{\circ} 14^{\prime} \mathrm{N}, 141^{\circ} 09^{\prime} \mathrm{E}\right)$ in the Sea of Japan $40 \mathrm{~km}$ off northern Hokkaido (Fig. 1). We randomly chose eight breeding males and two partners during the early June incubation period of 2009 (Kazama et al. 2008). The gender of individuals was confirmed following close observation of their mating behavior. GLS (GLS-Mk5, 19×17×7 mm, $3.7 \mathrm{~g}$, built by the British Antarctic Survey, UK; Afanasyev 2004) were attached to birds using plastic leg bands. The total mass of the GLS including the band was $5.6 \mathrm{~g}(<0.9 \%$ of the mean body mass $[ \pm \mathrm{SD}]$ of the 10 captured gulls $[644.3 \pm 110 \mathrm{~g}])$.

Two males (id 9090 and 9091) returned to the colony and bred in 2010, while the other two males (id 9083 and 9087) were not found in the breeding area in 2010, despite an extensive search. We considered that they were therefore taking a sabbatical as they returned to the colony and bred in 2011. These four males were recaptured when they were incubating. The other six individuals were not recaptured; one male returned, but did not breed, while the others did not return to the colony. 
Positioning The GLS records time, light intensity, immersion in seawater and water temperature (see details in Takahashi et al. 2008). Light data were analyzed with the 'TransEdit' and 'BirdTracker' software developed by the British Antarctic Survey. Sunset and sunrise times were estimated from thresholds in the light curves; latitude was derived from day length, and longitude from the time of local midday with respect to Greenwich Mean Time and Julian day, providing two locations per day (Phillips et al. 2004). night were identified and removed. Furthermore, location errors were minimized by comparing the water temperature experienced by birds and remotely sensed 8-day intermittent periods (several hours) of darkness during daylight hours when gulls were

112 at their nests (K. Kazama personal observation). The data for birds 9083 and 9087 did

113 not show these characteristic patterns, further confirming that they did not breed in 1142010. 

The spatial errors inherent in GLS tracking is around $186 \mathrm{~km}$ (Phillips et al. 2004). So we visualized the overall movement patterns using half-monthly (15 or 16 days) spatial medians of the valid daily latitude and longitude following Guilford et al.

118 (2011). Migration maps for the gulls were created with Arc View ver. 9.1 (ESRI, Inc.).

Activities The number of times gulls landed on water per day was calculated using the GLS wet/dry immersion data (Yamamoto et al. 2008) and used as an index of foraging activity. Black-tailed Gulls continuously make aerial plunge dives over fish schools identified such feeding bouts (intermittent wet and dry) which continued for at least 10 min, following McKnight et al. (2011). Although such records probably include non-foraging behaviors (e.g., preening, intensive scratching, or stretching), we believe that water landings are probably a reasonable indicator of foraging activity for gulls when compared between years (i.e., breeding versus sabbatical).

Gull species show considerable nocturnal foraging behavior (Burger and Staine 1993; Garthe and Hüppop 1996). Four males from this study also showed foraging activity during the nighttime, with an average 20.4 landings per night compared to an average of 22.7 landings per day. Therefore, activity data collected during both day and night were used in our analyses.

We employed a Generalized Linear Mixed Model (GLMM) with Poisson error distributions including the number of landings on the water per day as a dependent variable. First, to examine the general seasonal variation in foraging activities during the post-breeding period, we included the period (autumn migration, wintering, spring migration) in the model as a categorical fixed effect. Then, to test our hypothesis that 
individuals forage more intensively in the year prior to breeding than before a sabbatical,

140 we also included whether the individual skipped a breeding in the next breeding season

141 (i.e., data from id 9083 and 9087 in 2009-2010) or not, and included an interaction term

142 of the period and the year (before sabbatical or breeding) in the model as fixed effects.

143 We included individual identity as a random effect. Data from the sabbatical summer

144 was not included in this analysis. The analysis was conducted using R ver. 2.12.1 (R

145 Development Core Team 2010). Activity data for id 9087 were unavailable for 42 days

146 in 2011 due to occasional corruption in the logger memory.

\section{RESULTS}

149 Migration Migration routes and wintering areas differed among the four males (Fig. 1).

150 Three males moved southward along the west coast of Hokkaido after breeding, but bird 9083 moved around the east coast. During autumn three birds spent approximately two months in eastern Hokkaido, but bird 9090 stayed on the western coast of Hokkaido (Fig. 1e). All moved southward through the Sea of Japan and rapidly reached their wintering areas (west of $135^{\circ} \mathrm{E}$, Fig. 1a-f). Bird 9083 wintered west of Kyushu, while the others wintered in areas in the southwestern part of the Sea of Japan. Japan during March, and returned to their breeding colony in late April and bred again in 2010 (Fig. 1e and f). Birds 9083 and 9087 also moved northward in March, reached the breeding area in April and stayed around the colony during May and June, but did not breed in 2010 (Fig. 1a and c). They showed similar migration routes and reached the same wintering areas as in the previous year, and returned to the colony where they bred in 2011 (Fig.1a-d). 

period during early May to late June (the normal breeding period on Rishiri island; Kazama et al. 2008) for 9083 and 9087 in 2010 as a 'sabbatical summer'. We also defined the period before wintering as the 'autumn migration' and the period after wintering as the 'spring migration'.

Activities According to the overall GLMM model foraging activity showed statistically significant variation depending on period $(\mathrm{Z}=22.54, \mathrm{p}<0.001)$, type of year (before sabbatical or before breeding; $Z=-5.67, \mathrm{p}<0.001$ ) as well as on the interaction between period and type of year $(Z=-20.42, p<0.001)$. With regards to general seasonal variation in foraging activities, all individuals made significantly more landings on water per day during the winter $(Z=25.26, p<0.001$, Fig. $2 b)$ and during spring migration $(Z=18.23$, p $<0.001$, Fig. 2c), compared with the autumn migration (Fig. 2a). In relation to our hypothesis concerning differences in foraging activities prior to a breeding season or prior to a sabbatical season, individuals in the year prior to a sabbatical (i.e., birds 9083 and 9087 in 2009-2010) landed on water significantly more frequently each day than in the year before breeding during both the autumn migration $(Z=5.31, p<0.001$, Fig. $2 a)$ and the winter $(\mathrm{Z}=4.92, \mathrm{p}<0.001$, Fig. $2 \mathrm{~b}$ ), but did not do so during the spring migration $(\mathrm{Z}=-0.65, \mathrm{p}=0.52$, Fig. $2 \mathrm{c})$.

\section{DISCUSSION}

We present the first records of year-round movements and activities of Black-tailed

Gulls during both breeding and sabbatical years. In support of our hypothesis, sabbatical males migrated and returned to the area around of their colony in a similar manner to 
their behavior in a breeding year, even though their movements were not constrained by breeding duties. Social factors may explain why sabbatical gulls return and remain around the breeding colony even though they do not breed. It has been shown for several bird species that individuals are more likely to lose their breeding site, territory, or mate, after skipping a breeding season (Mougin et al. 1997; Pyle et al. 2001;

Bruinzeel 2007). Nevertheless, two sabbatical gulls nested at the same nest-site in both the 2009 and 2011 breeding seasons. Thus, they may have returned to the area around territories (mate fidelity was not known). Alternatively, sabbatical gulls may have visited the area around the colony in order to forage more effectively since the northern part of the Sea of Japan supports higher primary productivity than the southern part during late spring and early summer (Yamada et al. 2004).

All individuals showed similar seasonal patterns of foraging activity;

individuals foraged more actively during winter and spring migration compared with the autumn migration. Such general seasonal foraging patterns of migratory seabirds may be affected by seasonal differences in prey availability or the physiological condition of individuals (Green et al. 2005; Grémillet et al. 2005). Our results indicate that those environmental or physiological factors could constrain seasonal foraging patterns during the post-breeding season of all individuals, regardless of whether it was a breeding or a sabbatical year. intensively during the autumn migration and wintering periods than before a sabbatical (Fig. 2). Among seabirds, individuals are more likely to skip subsequent breeding when they invest more energy in previous breeding attempts (Le Bohec et al. 2007). Our 
results may indicate that sabbatical gulls attempt to forage more intensively, in order to

212 recover body condition immediately after the breeding season, until the following

213 wintering period. Conversely, during spring migration individuals showed similar

214 foraging frequencies in both sabbatical and breeding years. The reasons for this are unclear. All individuals, regardless of breeding or sabbatical state, may increase their foraging effort during the spring migration period in order to enhance their body condition in preparation for the following breeding attempt, and thus the differences in foraging activity between breeding and sabbatical birds might disappear.

A bird's decision to breed may depend on a range of physiological factors, such as fat accumulation or immunological condition, immediately prior to the breeding season (Giudici et al. 2010; Goutte et al. 2010). Sabbatical gulls may not be able to recover their body condition, despite foraging intensively during autumn and winter. The lack of plasticity in migratory routes and timing (Pulido 2007) could be among the causes of this paradoxical relationship between foraging effort during the post-breeding in other seabird species (Weimerskirch and Wilson 2000; Phillips et al. 2005; Guilford et al. 2011; but see Dias et al. 2011). Furthermore, individuals did not alter their seasonal patterns of foraging activities. If individual gulls need to follow the same route, timing, and seasonal foraging patterns due to migratory constraints such as navigation (Newton 2010) or because of environmental or physiological constraints (Berthold 1996), they may fail to match their foraging effort with local resource availability (Both and Visser 2001; Durant et al. 2007; Dias et al. 2011). Such failure to match effort to resource availability may lead to skipped breeding. 
We thank K. Kosugi, M. Sato, R. Sato, N. Takahashi, J. Kaji, K. Nakaya, T. Kawabata,

T. Nishijima, K. Nishijima, S. Okada, and H. Fujii for their support and assistance in the field. We are grateful to T. Alerstam and one anonymous referee for their very helpful comments and suggestions to improve the manuscript. We would also like to thank Mark Brazil, Scientific Editing Services, for assistance in the preparation of the final draft of the manuscript. Hokkaido Soya sub-prefectural office gave us permission to work on the Black-tailed Gulls in the study areas on Rishiri Island. This study was conducted with support by the Strategic Research Foundation Grant-aided Project for and Technology, Japan (MEXT).

Afanasyev V. 2004. A miniature daylight level and activity data recorder for tracking animals over long periods. Mem Natl Inst Polar Res 58: 227-233.

Berthold P. 1996. Control of Bird Migration. Chapman \& Hall, London, UK.

Both, C. and M. E. Visser. 2001. Adjustment to climate change is constrained by arrival date in a long-distance migrant bird. Nature 411: 296-298.

Bruinzeel, L. 2007. Intermittent breeding as a cost of site fidelity. Behavioral Ecology and Sociobiology 61: 551-556.

Burger, J. 1988. Foraging Behavior in Gulls: Differences in Method, Prey, and Habitat. Colonial Waterbirds 11: 9-23.

Burger, J. and K. Staine. 1993. Nocturnal behavior of gulls in coastal New Jersey. 
Estuaries and Coasts 16: 809-814.

260

Calladine, J. and M. P. Harris. 1997. Intermittent breeding in the Herring Gull Larus argentatus and the Lesser Black-backed Gull Larus fuscus. Ibis 139:259-263.

Coulson, J. C. 2011. The Kittiwake. T \& AD Poyser, London, UK.

Danchin, E. and E. Cam. 2002. Can non-breeding be a cost of breeding dispersal? Behavioral Ecology and Sociobiology 51: 153-163.

Dias, M. P., J. P. Granadeiro, R. A. Phillips, H. Alonso, and P. Catry. 2011. Breaking the routine: individual Cory's shearwaters shift winter destinations between hemispheres and across ocean basins. Proceedings of the Royal Society B: Biological Sciences 278: 1786-1793.

Durant, J. M., D. Ø. Hjermann, G. Ottersen, and N. C. Stenseth. 2007. Climate and the match or mismatch between predator requirements and resource availability. Climate Research 33: 271-283.

Garthe, S. and O. Hūppop. 1996. Nocturnal Scavenging by Gulls in the Southern North Sea. Colonial Waterbirds 19: 232-241.

Giudici, A., J. Navarro, C. Juste, and J. González-Solís. 2010. Physiological ecology of breeders and sabbaticals in a pelagic seabird. Journal of Experimental Marine Biology and Ecology 389:13-17.

Goutte, A., É. Antoine, H. Weimerskirch, and O. Chastel. 2010. Age and the timing of breeding in a long-lived bird: a role for stress hormones? Functional Ecology 24:1007-1016.

Green, J. A., I. L. Boyd, A. J. Woakes, N. L. Warren, and P. J. Butler. 2005. Behavioural flexibility during year-round foraging in macaroni penguins. Marine Ecology Progress Series 296:183-196. 
Grémillet, D., G. Kuntz, A. J. Woakes, C. Gilbert, J.-P. Robin, Y. Le Maho, and P. J. Butler. 2005. Year-round recordings of behavioural and physiological parameters reveal the survival strategy of a poorly insulated diving endotherm during the Arctic winter. Journal of Experimental Biology 208:4231-4241.

Guilford, T., R. Freeman, D. Boyle, B. Dean, H. Kirk, R. Phillips, and C. Perrins. 2011. A dispersive migration in the Atlantic Puffin and its implications for migratory navigation. Plos One 6: e21336.

Kazama, K., Y. Niizuma, and Y. Watanuki. 2012. Consistent individual variation in aggressiveness and behavioral syndrome across breeding contexts in changing environment in the Black-tailed Gull. Journal of Ethology 30: 279-288.

Kazama K, Tomita N, Ito M, Niizuma Y, Takagi M and Watanuki Y. 2008. Responses in breeding behaviour of Black-tailed Gull Larus crassirostris to different marine environments. In: Okada H, Mawatari SF, Suzuki N \& Gautam P (eds) Proceedings of International Symposium "The Origin and Evolution of Natural diversity”, 1-5 October 2007, Sapporo. pp. 215-220. Hokkaido-University Press, Hokkaido.

Le Bohec, C., M. Gauthier-Clerc, D. Gremillet, R. Pradel, A. Bechet, J. P. Gendner, and Y. Le Maho. 2007. Population dynamics in a long-lived seabird: I. Impact of breeding activity on survival and breeding probability in unbanded king penguins. Journal of Animal Ecology 76: 1149-1160.

McKnight, A., D. B. Irons, A. J. Allyn, K. M. Sullivan, and R. M. Suryan. 2011. Winter dispersal and activity patterns of post-breeding black-legged kittiwakes Rissa tridactyla from Prince William Sound, Alaska. Marine Ecology Progress Series 442: 241-253. 
Mougin, J.L., Jouanin, C.H.R., and Roux, F. 1997. Intermittent breeding in Cory's Shearwater Calonectris diomedea of Selvagem Grande, North Atlantic. Ibis 139: $40-44$.

Mouritsen, H. 2003. Spatiotemporal orientation strategies of long-distance migrants. In: Avian Migration (Eds: Berthold, Gwinner \& Sonnenschein), Springer Verlag: Berlin, Heidelberg, pp. 493-513.

Newton I. 2010. Bird Migration. Harper Collins Publishers, London, UK.

Phillips RA, Silk JRD, Croxall JP, Afanasyev V, Briggs DR. 2004. Accuracy of geolocation estimates for flying seabirds. Mar Ecol Prog Ser 266: 265-272.

Phillips, R. A., J. R. D. Silk, J. P. Croxall, V. Afanasyev, and V. J. Bennett. 2005. Summer distribution and migration of nonbreeding albatrosses: Individual consistencies and implications for conservation. Ecology 86: 2386-2396.

Pulido, F. 2007. Phenotypic changes in spring arrival: evolution, phenotypic plasticity, effects of weather and condition. Climate Research 35: 5-23.

Pyle, P., W. J. Sydeman, and M. Hester. 2001. Effects of age, breeding experience, mate fidelity and site fidelity on breeding performance in a declining population of Cassin's auklets. Journal of Animal Ecology 70:1088-1097.

R Developmental Core Team. 2010. R: A language and environment for statistical computing. R Foundation for Statistical Computing, Vienna, Austria. ISBN3-900051-07-0, URL http://www.R-project.org

Rice D. W. and Kenyon, K. W. 1962. Breeding cycles and behavior of Laysan and Black-footed Albatrosses. Auk 79: 517- 567

Spear, L. B. and D. G. Ainley. 1997. Flight speed of seabirds in relation to wind speed and direction. Ibis 139: 234-251. 
Stearns, S.C. 1992. The Evolution of Life Histories. Oxford University Press, Oxford.

Takahashi, A., D. Ochi, Y. Watanuki, T. Deguchi, N. Oka, V. Afanasyev, J. W. Fox, and P. N. Trathan. 2008. Post-breeding movement and activities of two Streaked Shearwaters in the north-western Pacific. Ornithological Science 7:29-35.

Watanuki Y. 1987. Inter- and intra-specific differences in feeding habit in Laridae $(\mathrm{PhD}$ thesis). Hokkaido University, Hokkaido (in Japanese).

Williams, G.C. 1966. Natural selection, the costs of reproduction, and a refinement of Lack's principle. American Naturalist 100: 687-690.

Weimerskirch H and Wilson RP. 2000. Oceanic respite for wandering albatrosses. Nature 406: 955-956.

Yamada, K., J. Ishizaka, S. Yoo, H.-c. Kim, and S. Chiba. 2004. Seasonal and Trathan. 2008. The lunar cycle affects at-sea behaviour in a pelagic seabird, the streaked shearwater, Calonectris leucomelas. Animal Behaviour 76: 1647-1652.

Yamamoto, T., A. Takahashi, N. Katsumata, K. Sato, and P. N. Trathan. 2010. At-Sea Distribution and Behavior of Streaked Shearwaters (Calonectris leucomelas) 
Figure legends

Fig. 1 Migratory tracks of four male Black-tailed Gulls breeding on Rishiri Island, northernmost Japan, during one (e, f) or two successive years (a-b and c-d). Position estimates are given every half-month (15 or 16 days) as spatial medians of available daily data. Months are indicated by numbers within circles (January $=1)$. Breeding season data (May to June) are excluded, except for the sabbatical year (for ID 9083 (b) and 9087 (d) in 2010). Colony locations are indicated by a C within a star. Lines join each individual gull's successive positions, but do not indicate the path travelled. 'Wintering' is defined as the period when the estimated half-monthly positions of gulls were located west of $135^{\circ} \mathrm{E}$ (dashed line).

Fig. 2 The number of landings made on water per day for four male Black-tailed Gulls during: (a) autumn migration, (b) wintering, and (c) spring migration periods, before a sabbatical and before breeding, and during (d) the sabbatical summer period. Means \pm SE are shown. Gray symbols indicate data recorded during 2009-2010 and black symbols refer to 2010-2011. Data obtained from the same individual in different years are connected by lines. Numbers to the left or right of the plots indicates sample sizes, given as days that are categorized into each period for each individual. The GLMM indicates that the total number of landings made on water is significantly higher $(\mathrm{p}<0.001)$ before a sabbatical (two plots with asterisks) than before breeding (the other four plots) in the wintering and autumn migration periods. 

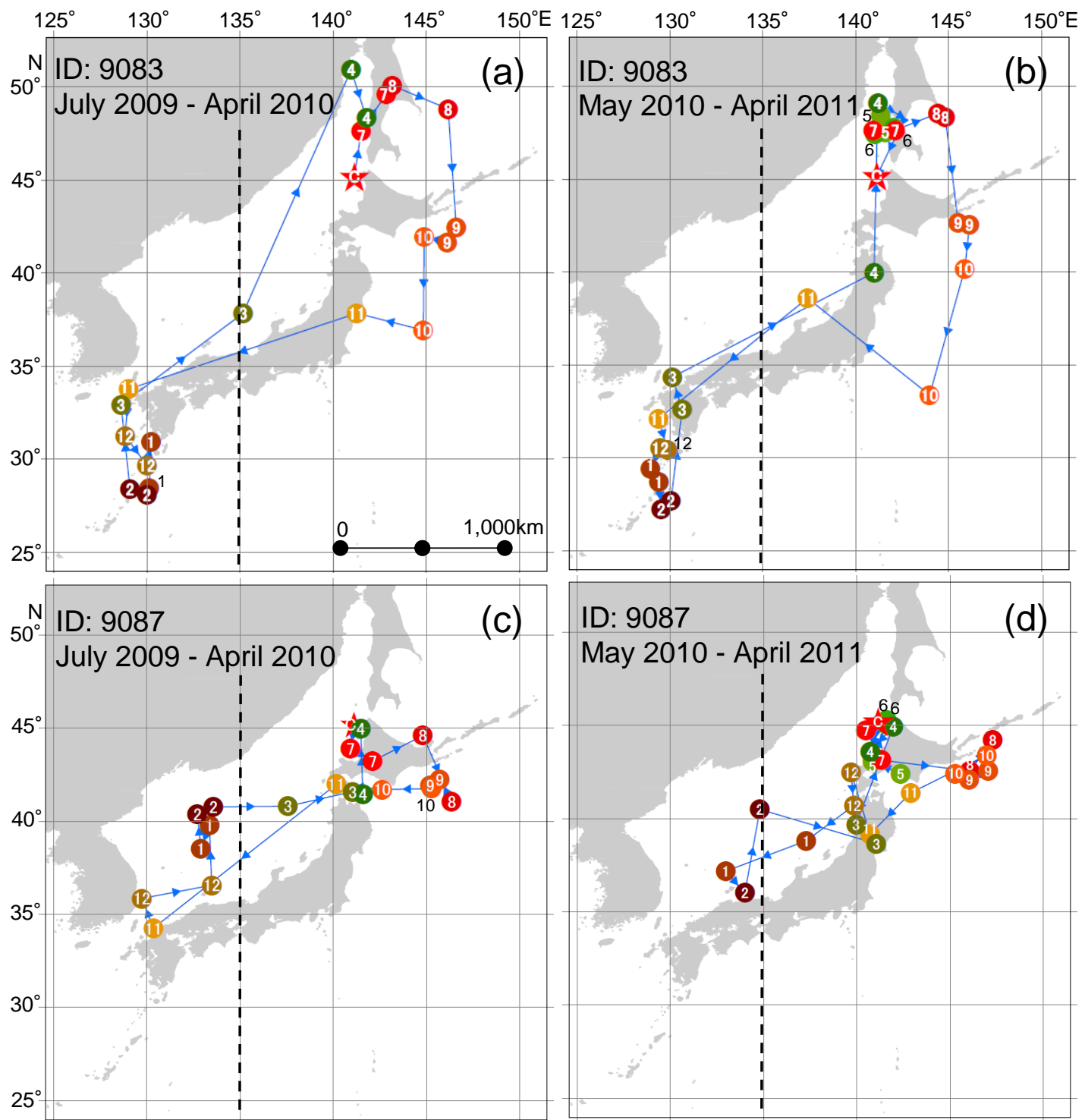

ID: 9087

May 2010 - April 2011

(d)
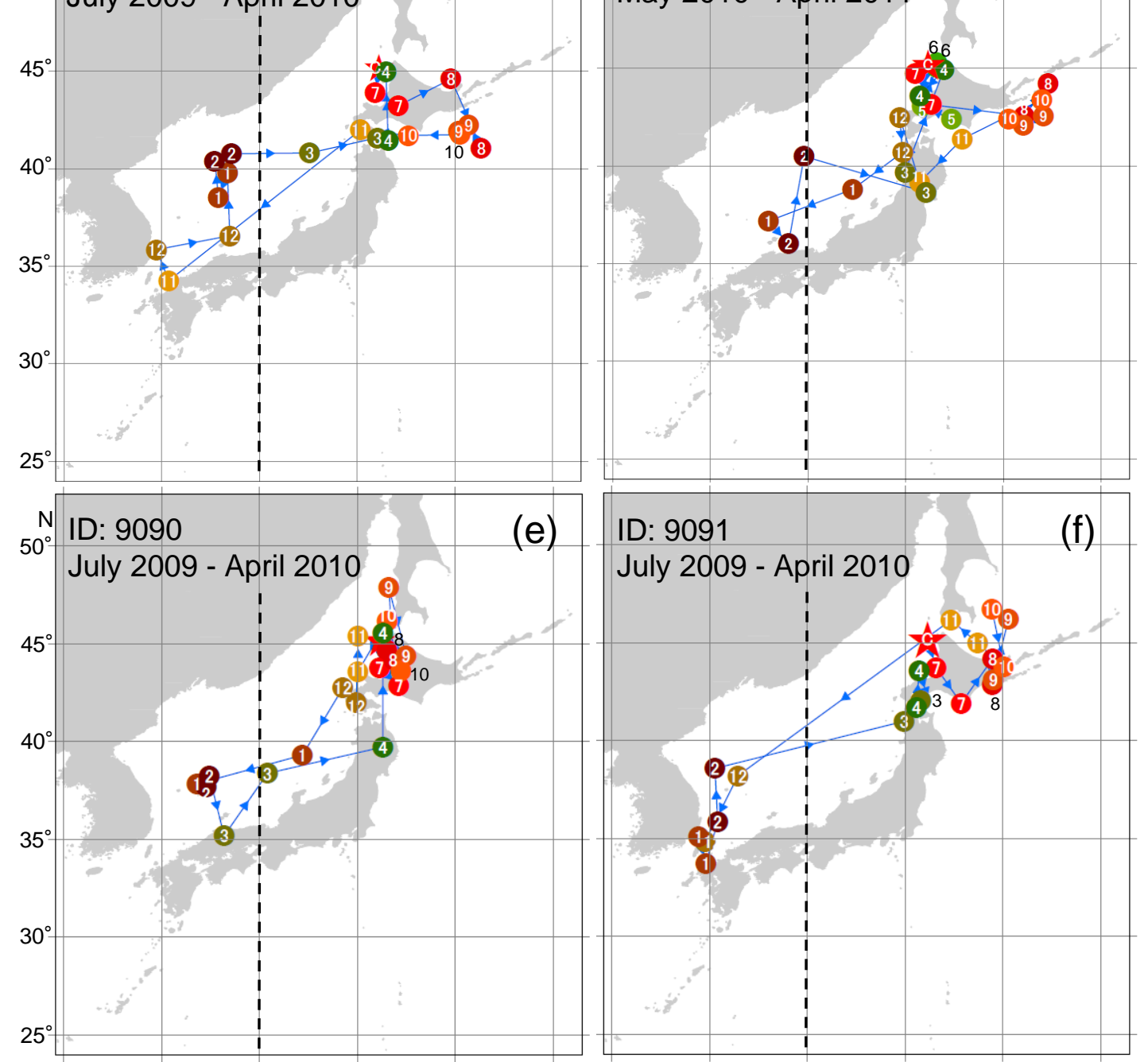

ID: 9091

(f)

July 2009 - April 2010

Fig. 1 


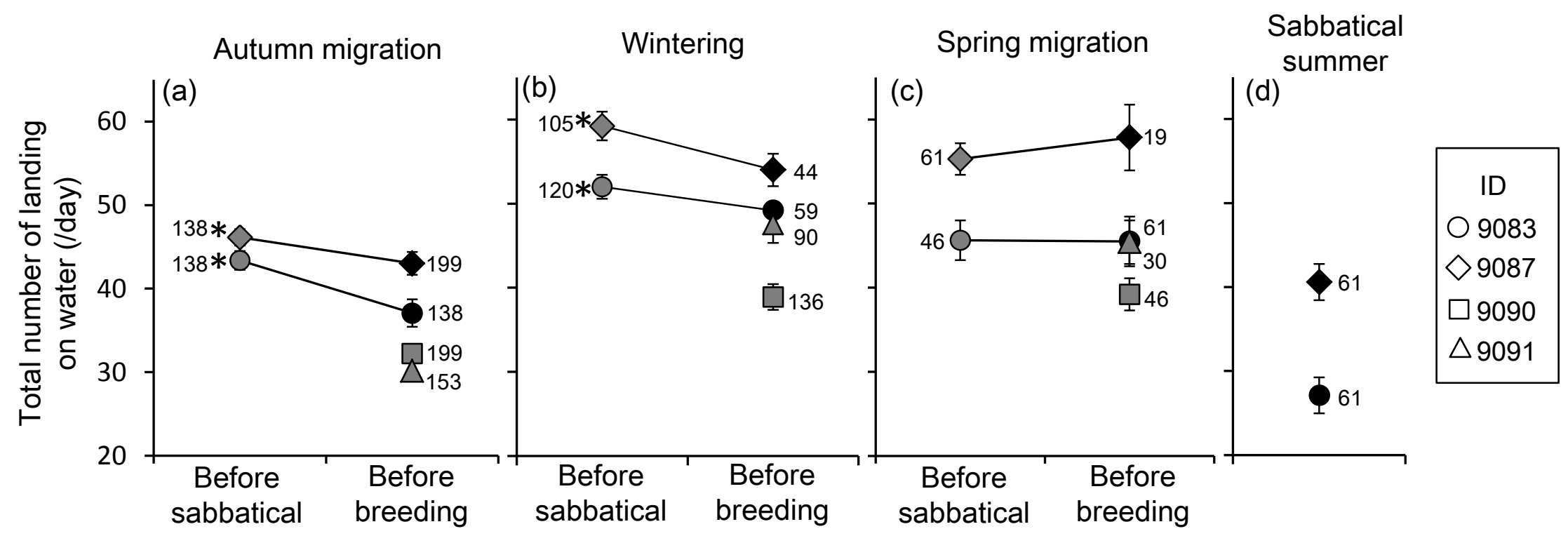

Fig. 2 